\title{
Bone Health in Pediatric Fracture Patients: A DEXA Study
}

\section{Barbara Minkowitz* , Jennifer Ristic, Leah Nadel, Meghan McDermott, Violet Wallerstein, Eileen Poletick}

Department of Orthopedics, Morristown Medical Center, Goryeb Children's Hospital, Atlantic Health Systems, Morristown, NJ, USA

Email: *barbara.minkowitz@atlantichealth.org

How to cite this paper: Minkowitz, B., Ristic, J., Nadel, L., McDermott, M., Wallerstein, V. and Poletick, E. (2022) Bone Health in Pediatric Fracture Patients: A DEXA Study. Open Journal of Orthopedics, 12, 57-65. https://doi.org/10.4236/ojo.2022.122007

Received: January 19, 2022

Accepted: February 20, 2022

Published: February 23, 2022

Copyright $\odot 2022$ by author(s) and Scientific Research Publishing Inc. This work is licensed under the Creative Commons Attribution International License (CC BY 4.0).

http://creativecommons.org/licenses/by/4.0/

(c) (i) Open Access

\begin{abstract}
Vitamin D deficiency is widespread in children and is associated with increased fracture severity. Previous studies have shown mixed results on the impact of vitamin D supplementation on bone health parameters measured on dual-energy x-ray absorptiometry (DEXA) scan. This is the first longitudinal DEXA study in a pediatric fracture population. Pediatric fracture patients with vitamin D levels below $20 \mathrm{ng} / \mathrm{mL}$ were counseled to take vitamin $\mathrm{D}$ and calcium per a serum-based protocol. Patients underwent baseline DEXA within the initial 12 weeks post fracture and had follow-up scans at 6 and 12 months. 48 patients were enrolled, 32 patients completed two DEXA scans, and 19 completed three DEXA scans. There was a significant increase in lumbar spine BMC, TBLH BMD, and TBLH BMC between DEXA 1 and 2 (p $<0.001)$. A positive trend in DEXA parameters is suggested between DEXA 1 and DEXA 3. Height adjusted z-scores (HAZ) were calculated which showed no statistical significance, $p$-values $>0.05$. In this group, there are no significant changes in TBLH, BMC or BMD z-scores one year after fracturing despite vitamin $\mathrm{D}$ and calcium supplementation. This suggests that children returning to collision sports may be at continued risk for refracture and future studies are needed.
\end{abstract}

\section{Keywords}

Bone Health, Pediatric, Fracture, Vitamin D, DEXA, Osteoporosis, Osteopenia, Vitamin D Deficiency

\section{Introduction}

Vitamin $\mathrm{D}$ is an important nutrient that impacts skeletal development by controlling levels of parathyroid hormone (PTH) and increasing calcium absorption 
[1] [2]. Vitamin D is primarily obtained from the sun, but $5 \%$ is from dietary intake [3]. Vitamin D deficiency is especially widespread in the winter. Even in areas with year-round sun, most children are found to have low vitamin D levels [4] [5]. In a survey of vitamin D levels in children in the US, $70 \%$ of the population was found to be either deficient or insufficient regardless of season (Vitamin D level less than $30 \mathrm{ng} / \mathrm{mL}$ serum 25(OH)D) [6].

Recent research has correlated low vitamin D levels with fracture severity and need for surgical treatment of fractures [7]. A study of Australian children showed $52 \%$ of pediatric patients with fractures were vitamin D deficient $(<11.6 \mathrm{ng} / \mathrm{mL}$ serum 25(OH)D) and low Vitamin D levels have been positively correlated with forearm fracture risk in African American children [8] [9]. The large number of fracture patients with vitamin $\mathrm{D}$ deficiency lends evidence to the fact that vitamin $\mathrm{D}$ is a necessary component for bone health.

Randomized controlled studies have shown mixed results, with some studies finding little to no impact of vitamin $\mathrm{D}$ on bone health parameters including bone mineral content (BMC) or bone mineral density (BMD) measured on dual-energy $x$-ray absorptiometry (DEXA) scan [10] [11]. A study conducted in Lebanese adolescents given either a placebo, 200 IU/day vitamin D, or 2000 IU/day, did not find significant changes in overall BMC or BMD [11].

Other studies have found a positive impact of vitamin $\mathrm{D}$ on bone health and BMD [12] [13] [14] [15]. One randomized control trial found higher BMD in those taking vitamin D supplementation of $35 \mathrm{ug} /$ week (1400 international units (IU)) or $350 \mathrm{ug} /$ week, (14,000 IU) versus the control group [15]. Lehtonen et al. found $27 \%$ higher lumbar spine BMD in Tanner stage III or IV females with "higher" serum level of $25(\mathrm{OH}) \mathrm{D}($ mean $=18.1 \mathrm{ng} / \mathrm{mL})$ compared to "low" serum $25(\mathrm{OH}) \mathrm{D}$ levels $($ mean $=7.7 \mathrm{ng} / \mathrm{mL}$ ) suggesting that the last premenarchal years are the most important for vitamin $\mathrm{D}$ to have an impact on overall $\mathrm{BMD}$ [14].

A study examining adolescent Finnish girls found a $14.3 \%$ increase in femur BMC in those taking 5 ug (200 IU) Vitamin D3 daily, versus 17.2\% increase in femur BMC in the group receiving $10 \mathrm{ug}$ (400 IU) compared to placebo after 1 year of intervention $(p=0.024)$ [13].

Research suggests that providing calcium and vitamin $\mathrm{D}$ together is more successful than either alone [1] [16] [17]. With $80 \%$ or better compliance with vitamin D and calcium supplementation, there was a $25 \%$ reduction in hip fractures in adults compared to control [17].

This study aims to study the effects of providing supplemental vitamin D and calcium on total BMC and BMD at 6 months and 12 months in pediatric fracture patients. A fracture population in children has not been studied. This is a special situation since having a fracture causes systemic release of a cascade of growth factors in the body to allow for fracture healing. The hypothesis is that this population will react differently to supplementation than those without fractures. Parathyroid hormone (PTH) and osteocalcin have been shown to increase after a fracture [18] [19]. Levels of insulin-like growth hormone 1 (IGF-1) 
were lower and remained lower in fracture patients one-year post-fracture compared to non-fracture patients [18]. There is also increased secretion of tumor necrosis factor-a and interleukins during fracture healing that work to recruit necessary cells to heal the bone [20]. Mesenchymal stem cells are particularly important in fracture healing and are recruited in part by BMPs, SDF-1, and CXRC-4 [20]. Overgrowth has been reported as a common occurrence in fracture patients. Bones on the same limb of the body as the fracture may grow longer than the contralateral side, due to the increased blood flow, and factors needed for bone formation [21]. Overgrowth is largely completed by 18 months post-fracture [21].

This is the first study to examine changes in DEXA parameters over time in a pediatric fracture population taking supplemental vitamin $\mathrm{D}$ and calcium. This study seeks to contribute to a body of knowledge on pediatric bone health, which is currently lacking as most studies focus on bone health in older populations. Information from this study can help with counseling children on safe return to sports based on DEXA results.

\section{Methods}

Institutional Review Board approval was obtained, and all patients gave informed consent before participating in the study. This study was conducted by using a sample of pediatric patients with a recent fracture and serum vitamin D level below $20 \mathrm{ng} / \mathrm{mL}$. Patients were counseled by the orthopedic surgeon to take vitamin D and calcium as per a serum-based supplementation protocol. Patients with levels between 12 and $20 \mathrm{ng} / \mathrm{ml}$ were recommended $4000 \mathrm{IU}$ daily, and patients below $12 \mathrm{ng} / \mathrm{mL}$ were recommended 7000 IU daily, both with follow-up levels to determine if the dose of vitamin D was enough to raise their levels.

Patients underwent a baseline DEXA scan within the initial 12 weeks post fracture and had follow-up DEXA scans at 6 months and 12 months. Patients presenting with a fracture and a vitamin D level less than or equal to $20 \mathrm{ng} / \mathrm{mL}$ were offered enrollment in this study if they were able to get a DEXA scan in the first 12 weeks after the fracture occurred.

Patients exclusion criteria included: endocrinopathies, malabsorption syndromes, hematologic disorders, cancer, bone disorders, spine disorders/scoliosis, collagen vascular diseases, nutritional/eating disorders, organ failure/transplantation, kidney/liver disease among others. All fractures are eligible other than spine or pelvis because spine DEXA is being used. Fractures causing the patients to be nonambulatory for at least four weeks due to expected loss of bone from nonambulation were excluded. DEXAs cannot be performed if the patient is wearing a cast; thus those wearing a cast beyond 12 weeks from the date of injury were excluded.

When patients agreed to participate in the study, they were given an initial survey to complete which documented patient demographics, previous fractures, sports and exercise activities, family history of bone disease, diet, and current supplementation. Patients received a stipend totaling \$125 for participating in 
the study, with $\$ 25$ given as a gift card after the first DEXA, and $\$ 50$ gift cards given at the second and third DEXA scans to increase patient compliance.

At the time of the DEXA scan, a short survey was completed asking self-reported vitamin D, calcium, and multivitamin compliance and to self-identify their Tanner stage of development.

Patients were contacted via phone reminders about scheduling DEXA scans and continuing to take vitamins. Patients were considered compliant if at their follow-up scans, they reported taking vitamin D for at least four days per week.

\section{Results}

48 patients were enrolled, 32 patients completed the first two DEXA scans, and 19 completed the study with three DEXA scans. Demographics including Tanner stage at time of initial DEXA are presented in Table 1.

Table 1. Demographics.

\begin{tabular}{|c|c|}
\hline & $\mathrm{n}=48$ \\
\hline Age, mean (SD) & $12.375(0.397)$ \\
\hline \multicolumn{2}{|l|}{ Ethnicity, n (\%) } \\
\hline Hispanic or Latino & $17(35.42 \%)$ \\
\hline NOT Hispanic or Latino & $30(62.5 \%)$ \\
\hline Unknown/Not Reported & $1(2.08 \%)$ \\
\hline \multicolumn{2}{|l|}{ Race, n (\%) } \\
\hline Asian & $5(10.42 \%)$ \\
\hline Black or African American & $8(16.67 \%)$ \\
\hline More Than One Race & $1(2.08 \%)$ \\
\hline Native Hawaiian or Other Pacific Islander & $1(2.08 \%)$ \\
\hline Unknown/Not Reported & $3(6.25 \%)$ \\
\hline White & $30(62.5 \%)$ \\
\hline \multicolumn{2}{|l|}{ Skin Tone, $\mathrm{n}(\%)$} \\
\hline Dark & $16(34.04 \%)$ \\
\hline Light & $31(65.96 \%)$ \\
\hline \multicolumn{2}{|l|}{ Gender, $\mathrm{n}(\%)$} \\
\hline Female & $20(41.67 \%)$ \\
\hline Male & $28(58.33 \%)$ \\
\hline Age menarche or puberty, $n$, mean (SD) & $16,12.063(2.016)$ \\
\hline Height (inches), mean (SD) & $60.834(6.158)$ \\
\hline Weight (pounds), mean (SD) & $111.38(37.38)$ \\
\hline BMI, mean (SD) & $20.654(4.731)$ \\
\hline \multicolumn{2}{|l|}{ Tanner Stage Girl, n (\%) } \\
\hline I & $2 / 14,(14.29 \%)$ \\
\hline II & $4 / 14,(28.57 \%)$ \\
\hline III & $1 / 14,(7.14 \%)$ \\
\hline IV & $7 / 14,(50 \%)$ \\
\hline \multicolumn{2}{|l|}{ Tanner Stage Boy, n (\%) } \\
\hline I & $5 / 23,(21.74 \%)$ \\
\hline II & $4 / 23,(17.39 \%)$ \\
\hline III & $5 / 23,(21.74 \%)$ \\
\hline IV & $6 / 23,(26.09 \%)$ \\
\hline V & $3 / 23,(13.04 \%)$ \\
\hline
\end{tabular}


There was a significant increase seen in lumbar spine BMC, TBLH BMD, and TBLH BMC between DEXA 1 and $2(\mathrm{p}<0.001$, Table 2$)$. A positive trend in DEXA parameters is suggested between DEXA 1 and DEXA 3, although not statistically significant. There was not a significant change in lumbar spine Z-score, TBLH Z-score, right or left femoral neck z-scores between DEXA 1 and 2 or DEXA 2 and 3 (Table 2).

Height adjusted z-scores (HAZ) were calculated using the Children's Hospital of Philadelphia's Pediatric Z-Score Calculator by Zemel [22]. Paired t-tests comparing changes from HAZ 1 to HAZ 3 for all measurements showed no statistical significance, $p$-values $>0.05$ ( $p=0.178 ; 0.066 ; 0.087 ; 0.313$; Figure 1$)$.

Table 2. DEXA data.

\begin{tabular}{|c|c|c|c|c|c|}
\hline & DEXA 1 & DEXA 2 & DEXA 3 & \multirow{2}{*}{$\begin{array}{l}\mathrm{p} \text {-value } \\
\text { TP1 and } \\
\text { TP2 }\end{array}$} & \multirow{2}{*}{$\begin{array}{c}\mathrm{p} \text {-value } \\
\text { TP2 and TP3 }\end{array}$} \\
\hline & $\mathrm{n}=32$ & $\mathrm{n}=32$ & $\mathrm{n}=19$ & & \\
\hline $\begin{array}{l}\text { Height in inches at time of } \\
1 \text { st DEXA, n, mean (SD) }\end{array}$ & $32,60.89(6.36)$ & $32,62.24(5.79)$ & $1,57\left(^{\star}\right)$ & $<0.001$ & unable to calc \\
\hline $\begin{array}{l}\text { Weight in pounds at time of } \\
1 \text { st DEXA, n, mean (SD) }\end{array}$ & $32,116.36(41.26)$ & $32,123.23(43.49)$ & $1,94.8\left(^{\star}\right)$ & $<0.001$ & unable to calc \\
\hline $\begin{array}{l}\text { BMI at time of 1st DEXA, n, } \\
\text { mean }(S D)\end{array}$ & $32,21.494(5.282)$ & $32,21.828(5.527)$ & - & 0.179 & unable to calc \\
\hline L/S BMD, n, mean (SD) & $32,0.9564(0.1972)$ & $32,0.9538(0.2528)$ & $19,1.0189(0.2195)$ & 0.908 & 0.013 \\
\hline L/S Z Score, $n$, mean (SD) & $32,0.116(1.267)$ & $32,0.016(1.298)$ & $19,0.347(1.111)$ & 0.034 & 0.917 \\
\hline L/S BMC, n, mean (SD) & $32,40.77(14.54)$ & $32,43.04(15.17)$ & $19,43.92(16.23)$ & $<0.001$ & 0.005 \\
\hline TBLH BMD, n, mean (SD) & $32,0.9189(0.1461)$ & $32,0.9445(0.1558)$ & $19,0.9696(0.1613)$ & $<0.001$ & 0.008 \\
\hline $\begin{array}{l}\text { TBLH Z Score, n, mean } \\
\text { (SD) }\end{array}$ & $25,0.304(1.368)$ & $25,0.316(1.422)$ & $14,0.516(1.347)$ & 0.851 & 0.06 \\
\hline TBLH BMC, n, mean (SD) & $32,1536(576)$ & $31,1614(602)$ & $19,1719(665)$ & $<0.001$ & 0.005 \\
\hline $\begin{array}{l}\text { Right Femoral Neck BMD, } \\
\text { n, mean }(S D)\end{array}$ & $19,0.9961(0.1629)$ & $21,1.0045(0.1679)$ & $14,1.0486(0.1868)$ & 0.251 & 0.161 \\
\hline $\begin{array}{l}\text { Right Femoral Neck Z } \\
\text { score, n, mean (SD) }\end{array}$ & $19,-0.016(1.326)$ & $21,0.081(1.443)$ & $14,0.5(1.468)$ & 0.636 & 0.591 \\
\hline $\begin{array}{l}\text { Right Femoral Neck Z } \\
\text { BMC, n, mean (SD) }\end{array}$ & $19,4.517(1.028)$ & $21,4.55(1.083)$ & $14,4.708(1.143)$ & 0.21 & 0.535 \\
\hline $\begin{array}{l}\text { Left Femoral Neck BMD, n, } \\
\text { mean (SD) }\end{array}$ & $20,1.0243(0.1635)$ & $21,1.0149(0.1577)$ & $14,1.0723(0.1862)$ & 0.897 & 0.069 \\
\hline $\begin{array}{l}\text { Left Femoral Neck Z score, } \\
\mathrm{n}, \text { mean }(\mathrm{SD})\end{array}$ & $20,0.27(1.449)$ & $21,0.167(1.412)$ & $14,0.679(1.396)$ & 0.285 & 0.38 \\
\hline $\begin{array}{l}\text { Left Femoral Neck Z BMC, } \\
\mathrm{n}, \text { mean }(\mathrm{SD})\end{array}$ & $20,4.521(0.914)$ & $21,4.479(1.013)$ & $14,4.761(1.09)$ & 0.425 & 0.036 \\
\hline $\begin{array}{l}\text { Grip strength \#1 (average of } \\
\text { test trials), } n, \text { mean (SD) }\end{array}$ & $32,42.66(17.13)$ & $32,48.47$ (18.59) & $18,49.83(15.35)$ & 0.001 & 0.226 \\
\hline
\end{tabular}




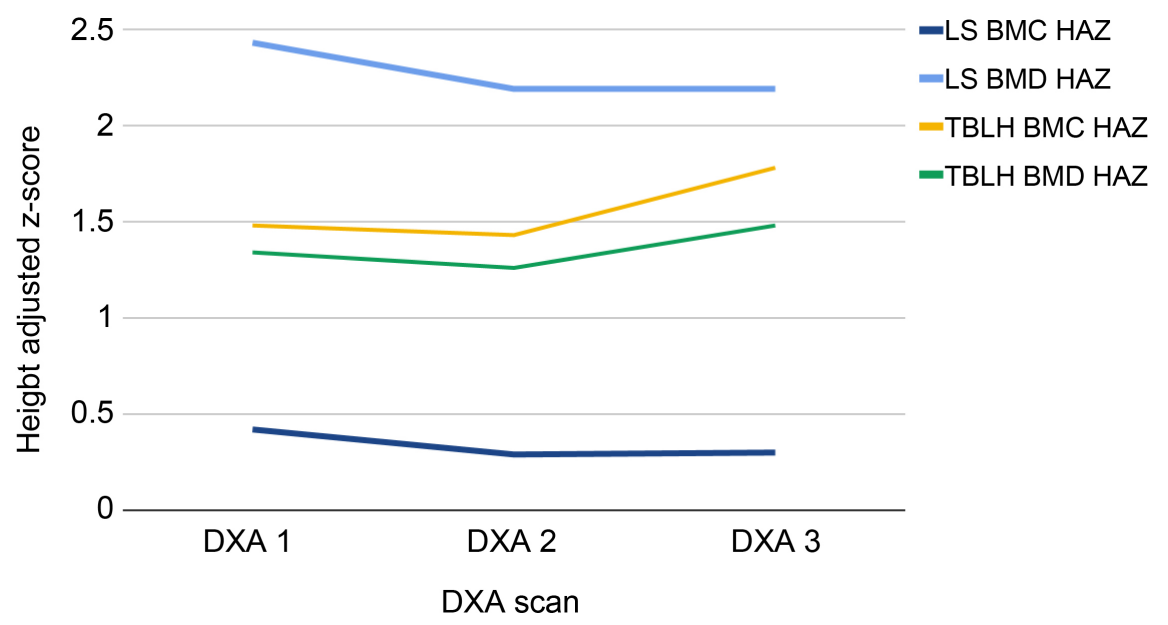

Figure 1. Height adjusted Z-scores over time for all measurements.

ANOVA tests compared the percent change in Tanner stage. While there was no statistical significance, the impact of Tanner stage is very high due to the high $\mathrm{R}^{2}$ value. The mean percent change by Tanner stage was highest for stage II in each variable except TBLH BMD, where stage III had a higher mean by almost $3 \%$.

Using Wilcoxon Sign Rank and correlation tests, it was determined that there was no significant difference in the time points for the supplementation compliant patients, and there was no significant difference in any of the measurements between compliant and non-compliant patients. A total of 15 patients were compliant, with 4 non-compliant patients.

After BMC and BMD were adjusted for height, there were no statistically significant changes found in any of the measurements.

\section{Discussion}

This study suggests that vitamin D supplementation in pediatric fracture patients has positive impacts on bone health, measured using DEXA scans obtained over 12-months with a positive trend seen. This is the first longitudinal DEXA study in a pediatric fracture population. In this group, there are no significant changes in TBLH, BMC or BMD z-scores one year after a fracture despite vitamin $\mathrm{D}$ and calcium supplementation. This suggests that children returning to collision sports may be at continued risk for injury or refracture and future studies are needed to explore this further.

The hormonal changes that occur after a fracture may be involved in resorbing bone to mobilize calcium for fracture healing and may have lowered the HAZs from DEXA 1 to 2 with no effect on DEXA 3. No one has studied this 6-month time point in this fracture population with or without supplementation and this could be studied further in the future.

Patients grew an average of 1.46 inches $(S D=1.09)$ during the study, which impacts the size of bones and therefore BMC and BMD. Growth over time was accounted for by calculating the HAZ for each patient, at each measurement, at 
each time point. More patients had a negative change after converting to HAZs, so it is likely due primarily to growth in the patients that have caused the increases in the raw data. It is expected that pediatric patients would have increased bone mass and density with the 12-month follow-up period due to normal growth, however, these results suggest a positive trend which may be amplified due to vitamin D and calcium supplementation. Even with the differences in growth, nearly all patients showed some increase in LS and TBLH BMC and $\mathrm{BMD}$, suggesting a role for vitamin $\mathrm{D}$ and calcium supplementation.

These study results vary from what is found in the literature. While many studies did not find an impact of vitamin D supplementation on bone mass or density, the doses of vitamin $\mathrm{D}$ were lower than the daily recommendations given in this study or much higher and less frequent [10] [11] [23]. Vitamin D supplementation in this study was per vitamin D serum level-based protocol. While other studies only found increases in bone density in the LS, this study showed far fewer positive impacts in that region and instead had increases in the TBLH measurement [12] [13].

Study limitations include a small sample size due to loss to follow-up and adherence to study protocol. Increasing patient compliance to supplementation and to follow-up DEXA scans in the future could improve conclusions that are able to be drawn from the study. Not all participants had follow-up serum 25(OH)D levels drawn as requested. Although repeat vitamin $\mathrm{D}$ testing is not advocated by many, this would have been one way to reliably measure whether study participants were compliant with supplementation. Further DEXA studies at 6 months post fracture could help elucidate the hormonal effect of fractures on bone health.

\section{Acknowledgements}

Stephanie Chiu is acknowledged for performing data statistical analysis.

\section{Contribution Statement}

BM: Conceptualization, Methodology, Formal analysis, investigation, Resources, Writing-Review \& editing, Supervision, Funding acquisition. JR: Methodology, investigation, writing-original draft \& review and editing, project administration. LN: Conceptualization, writing-original draft, project administration. MM: writing-original draft, investigation, data curation. VW: writing-review and editing, data curation, formal analysis. EP: conceptualization, methodology.

\section{Funding}

This research was supported by the pediatric bone health fund at Morristown medical center, Morristown, NJ.

\section{Competing Interests}

The authors declare there are no competing interests. 


\section{References}

[1] Rizzoli, R., Boonen, S., Brandi, M.L., Burlet, N., Delmas, P. and Reginster, J.Y. (2008) The Role of Calcium and Vitamin D in the Management of Osteoporosis. Bone, 42, 246-249. https://doi.org/10.1016/j.bone.2007.10.005

[2] Rizzoli, R., Bianchi, M.L., Garabedian, M., McKay, H.A. and Moreno, L.A. (2010) Maximizing Bone Mineral Mass Gain during Growth for the Prevention of Fractures in Adolescents and the Elderly. Bone, 46, 294-305.

https://doi.org/10.1016/j.bone.2009.10.005

[3] Vlachopoulos, D., Gracia-Marco, L., Barker, A.R., Huybrechts, I., Moreno, L.A. and Mouratidou, R. (2015) Bone Health: The Independent and Combined Effects of Calcium, Vitamin D, and Exercise in Children and Adolescents. In: Preedy, V.R., Ed., Food and Nutritional Components in Focus No. 10: Calcium: Chemistry, Analysis, Function and Effects, the Royal Society of Chemistry, UK, 530-546. https://doi.org/10.1039/9781782622130-00530

[4] Holick, M.F. (2008) Sunlight, UV-Radiation, Vitamin D and Skin Cancer: How Much Sunlight Do We Need? In: Reichrath J., Ed., Sunlight, Vitamin D and Skin Cancer, Springer, New York, 1-15. https://doi.org/10.1007/978-0-387-77574-6_1

[5] Kremer, R., Campbell, P.P., Reinhardt, T. and Gilsanz, V. (2009) Vitamin D Status and Its Relationship to Body Fat, Final Height, and Peak Bone Mass in Young Women. The Journal of Clinical Endocrinology \& Metabolism, 94, 67-73. https://doi.org/10.1210/jc.2008-1575

[6] Melamed, M.L. and Kumar, J. (2010) Low Levels of 25-Hydroxyvitamin D in the Pediatric Populations: Prevalence and Clinical Outcomes. Pediatric Health, 4, 89-97.

https://doi.org/10.2217/phe.09.72

[7] Minkowitz, B., Sawyer, A., Fun, E.B., Dvorzhinskiy, A. and Lane, J.M. (2018) The Answer is Vitamin D! From Pediatrics to Geriatrics in Orthopaedics. In: Parvizi, J., Huddleston, J.I., Eds., Instructional Course Lectures. Volume 67, American Academy of Orthopaedic Surgeons, Rosemont, Illinois, 529-542.

[8] Kwon, D.H., Krieser, D., Harris, C., Khot, A., Ebeling, P.R. and Rodda, C.P. (2016) High Prevalence of Vitamin D Deficiency in 2-17 Year Olds Presenting with Acute Fractures in Southern Australia. Bone Reports, 5, 153-157. https://doi.org/10.1016/j.bonr.2016.05.007

[9] Ryan, L.M., Brandoli, C., Freishtat, R.J., Wright, J.L., Tosi, L. and Chamberlain, J.M. (2010) Prevalence of Vitamin D Insufficiency in African American Children with Forearm Fractures: A Preliminary Study. Journal of Pediatric Orthopaedics, 30, 106-109. https://doi.org/10.1097/BPO.0b013e3181d076a3

[10] Cheng, S., Tylavsky, F., Kröger, H., Kärkkäinen, M., Lyytikäinen, A., Koistinen, A., Mahonen, A., Alen, M., Halleen, J., Vaananen, K. and Lamber-Allardt, C. (2003) Association of Low 25-Hydroxyvitamin D Concentrations with Elevated Parathyroid Hormone Concentrations and Low Cortical Bone Density in Early Pubertal and Prepubertal Finnish Girls. The American Journal of Clinical Nutrition, 78, 485-492. https://doi.org/10.1093/ajcn/78.3.485

[11] El-Hajj Fuleihan, G., Nabulsi, M., Tamim, H., Maalouf, J., Salamoun, M., Khalife, H., Choucair, M., Arabi, A. and Vieth, R. (2006) Effect of Vitamin D Replacement on Musculoskeletal Parameters in School Children: A Randomized Controlled Trial. The Journal of Clinical Endocrinology \& Metabolism, 91, 405-412. https://doi.org/10.1210/jc.2005-1436

[12] Wizenberg, T., Powell, S., Shaw, K.A. and Jones, G. (2011) Effects of Vitamin D Supplementation on Bone Density in Healthy Children: Systematic Review and Meta- 
Analysis. BMJ, 342, Article No. c7254. https://doi.org/10.1136/bmj.c7254

[13] Viljakainen, H.T., Natri, A.M., Markkainen, M., Huttunen, M.M., Palssa, A., Jakobsen, J., Cashman, K.D., Molgaard, C. and Lamberg-Allardt, C. (2006) A Positive DoseResponse Effect of Vitamin D Supplementation on Site-Specific Bone Mineral Augmentation in Adolescent Girls: A Double-Blinded Randomized Placebo-Controlled 1-Year Intervention. Journal of Bone and Mineral Research, 21, 836-844. https://doi.org/10.1359/jbmr.060302

[14] Lehtonen, et al. (2002) Vitamin D and Attainment of Peak Bone Mass among Peripubertal Finnish Girls: A 3-y Prospective Study. The American Journal of Clinical Nutrition, 76, 1446-1453. https://doi.org/10.1093/ajcn/76.6.1446

[15] Al-Shaar, L., Nabulsi, M., Maalouf, J., El-Rassi, R., Veith, R., Beck, T.J. and Fuleihan, G.E. (2013) Effects of Vitamin D Replacement on Hip Structural Geometry in Adolescents: A Randomized Controlled Trial. Bone, 56, 296-303.

https://doi.org/10.1016/j.bone.2013.06.020

[16] Zhu, K. and Prince, R.L. (2012) Calcium and Bone. Clinical Biochemistry, 45, 936942. https://doi.org/10.1016/j.clinbiochem.2012.05.006

[17] Jackson, R.D., LaCroix, A.Z., Gass, M., Wallace, R.B., Robbins, J., Lewis, C.E., Bassford, T., Beresford, S.A.A., Black, H.R., Blanchette, P., Bonds, D.E., Brunner, R.L., Brzyski, R.G., Caan, B., Cauley, J.A., Chlebowski, R.T., Cummings, S.R., Granek, I., Hays, J., Heiss, G., Hendrix, S.L., Howard, B.V., Hsia, J., Hubbell, A., Johnson, K.C., Judd, H., Kotchen, J.M., Kuller, L.H., Langer, R.D., Lasser, N.L., Limacher, M.C., Ludlam, S., Manson, J.E., Margolis, K.L., McGowan, J., Ockene, J.K., O’Sullivan, M.J., Phillips, L., Prentice, R.L., Satro, G.E., Stefanick, M.L., Van Horn, L., WactawskiWende, J., Whitlock, E., Anderson, G.L., Assaf, A.R. and Barad, D. (2006) Calcium Plus Vitamin D Supplementation and the Risk of Fractures. The New England Journal of Medicine, 354, 669-683. https://doi.org/10.1056/NEJMoa055218

[18] Cappola, A.R., Hawkes, W.G., Blocher, N., Yu-Yahiro, J., Orwig, D., Fredman, L., Miller, R.R., Guralnik, J.M. and Magaziner, J. (2012) The Hormonal Profile of Hip Fracture Female Patients Differs from Community-Dwelling Peers over a 1-Year Follow-Up Period. Osteoporosis International, 22, 339-344.

https://doi.org/10.1007/s00198-010-1187-4

[19] Ban, Z.N., Li, Z.J., Gu, Q.S., Cheng, J., Huan, Q. and Xing, S.X. (2019) Correlation of Serum PTH Level and Fracture Healing Speed in Elderly Patients with Hip Fracture. Journal of Orthopaedic Surgery and Research, 14, Article No. 361.

https://doi.org/10.1186/s13018-019-1413-5

[20] Marsell, R. and Einhorn, T.A. (2011) The Biology of Fracture Healing. Injury, 42, 551555. https://doi.org/10.1016/j.injury.2011.03.031

[21] Shapiro, F. (1981) Fractures of the Femoral Shaft in Children: The Overgrowth Phenomenon. Acta Orthopaedica Scandinavica, 52, 649-655.

https://doi.org/10.3109/17453678108992162

[22] Zemel, B.S., Leonard, M.B., Kelly, A., Lappe, J.M., Gilsanz, V., Oberfield, S., Mahboubi, S., Shepherd, J.A., Hangartner, T.N., Frederick, M.M., Winer, K.K., Kalkwarf, H.J. (2010) Height Adjustment in Assessing Dual Energy X-Ray Absorptiometry Measurements of Bone Mass and Density in Children. The Journal of Clinical Endocrinology \& Metabolism, 95, 1265-1273. https://doi.org/10.1210/jc.2009-2057

[23] Ward, K.A., Das, G., Roberts, S.A., Berry, J.L., Adams, J.E., Rawer, R. and Mughal, M.Z. (2010) A Randomized Controlled Trial of Vitamin D Supplementation upon Musculoskeletal Health in Postmenarchal Females. The Journal of Clinical Endocrinology \& Metabolism, 95, 4643-4651. https://doi.org/10.1210/jc.2009-2725 